\title{
Assessing Ventilation Skills by Nursing Students in Paediatric and Adult Basic Life Support: A Crossover Randomized Simulation Study Using Bag-Valve-Mask (BMV) vs Mouth-to-Mouth Ventilation (MMV)
}

\author{
Martín Otero-Agra',*, María Teresa Hermo-Gonzalo ${ }^{1,2}$, Myriam Santos-Folgar ${ }^{1,2}$, \\ Felipe Fernández-Méndez ${ }^{1,2,3}$, Roberto Barcala-Furelos ${ }^{1,3}$
}

${ }^{1}$ REMOSS Research Group. Faculty of Education and Sport Sciences. University of Vigo, Pontevedra, Spain

${ }^{2}$ University School of Nursing, University of Vigo, Pontevedra, Spain

${ }^{3}$ CLINURSID Network Research,

Department of Psychiatry, Radiology and Public Health, University of Santiago de Compostela, Santiago de

Compostela, Spain

\section{*Correspondence}

martinoteroagra@gmail.com

(Martín Otero-Agra)

\begin{abstract}
To evaluate nursing students' CPR skills using mouth-to-mouth (MMV) and bag-valvemask (BMV) ventilation techniques on manikin simulators for infant and adult victims after practical and theoretical training. A quasi-experimental randomised cross-over design study with 44 nursing students was carried out. The participants attended a 5-hour theoretical and practical CPR training session using MMV and BMV on adult and infant manikins. A month later, four 4-minute CPR tests were performed in pairs. Two tests were performed on the infant manikin and two on the adult, using the two ventilation techniques (MMV and BMV). No significant differences between the tests were observed in the quality of chest compression $(p>0.008)$. Significantly higher values of effective ventilations were observed with MMV as compared with BMV in both age groups: Adult (MMV: $98 \pm 7 \%$ / BMV: $84 \pm 17 \% / \mathrm{p}=0.003$ ) and Infant (MMV: $97 \pm 11 \%$ / BMV: $76 \pm 26 \% / \mathrm{p}=0.001$ ). CPR quality was significantly higher when using MMV on the infant $(68 \pm 16 \% ; \mathrm{p}<0.001)$ than in the other tests. The nursing students did not manage to master BMV with either victim. New complementary strategies to help them grasp the necessary BMV skills will be required.
\end{abstract}

Keywords

CPR training, Nursing students, BMV, MMV, Adult CPR, Paediatric CPR

\section{Introduction}

Cardiorespiratory arrest (CRA) is one of the main causes of death globally [1]. Between $20-40 \%$ of out-of-hospital CRAs are non-cardiac and show low survival rates $[2,3]$. In the paediatric environment, most arrests are respiratory-related $[4,5]$, showing low recovery rates $[6,7]$. The strategy of performing only compressions is very widespread among possible rescuers without a duty of care [8]. However, healthcare professionals should perform ventilations, especially in cardiac arrests (CA) of longer duration or noncardiac-related ones $[8,9]$. In paediatrics, the main cause of CRA is asphyxia, which requires early respiratory support in order to re-establish oxygen reserves [10-12].

Nurses are an element of staff who are generally the first responders to cardiac arrests in hospitals, clinics and other facilities $[13,14]$. The aim of healthcare staff with regard to $\mathrm{CPR}$ is to ensure the quality of the manoeuvres being performed. Despite having carried out training sessions, it is still a challenge for healthcare workers to achieve high CPR quality levels [14-16]. In particular, the mistakes that reduce CPR quality usually occur as a result of incorrect ventilation delivery skills $[17,18]$. Nursing staff learn how to perform basic ventilation techniques during their university degree training. The techniques used when performing insufflations during practical training are mouth-to-mouth ventilation (MMV) and bag-valve-mask ventilation (BMV). These simple ventilation techniques are widespread, and both are effective in successfully performing insufflations [19]. Nursing students are also possible first responders and future nurses. Mastering BMV requires more experience and there is evidence that students do not use it as effectively as MMV [20]. In spite of this, there is scant evidence provided by random designs thus making it hard to evaluate which of the two is better applied [21].

The aim of this study was to evaluate nursing students' CPR skills with two ventilation techniques (MMV and BMV) in adult and infant victim simulation manikins after a practical and theoretical 5-hour training session.

\section{Methods}

\subsection{Sample}

A total of 44 nursing students from Vigo University (Spain) took part in this study. We used a convenience sample by 


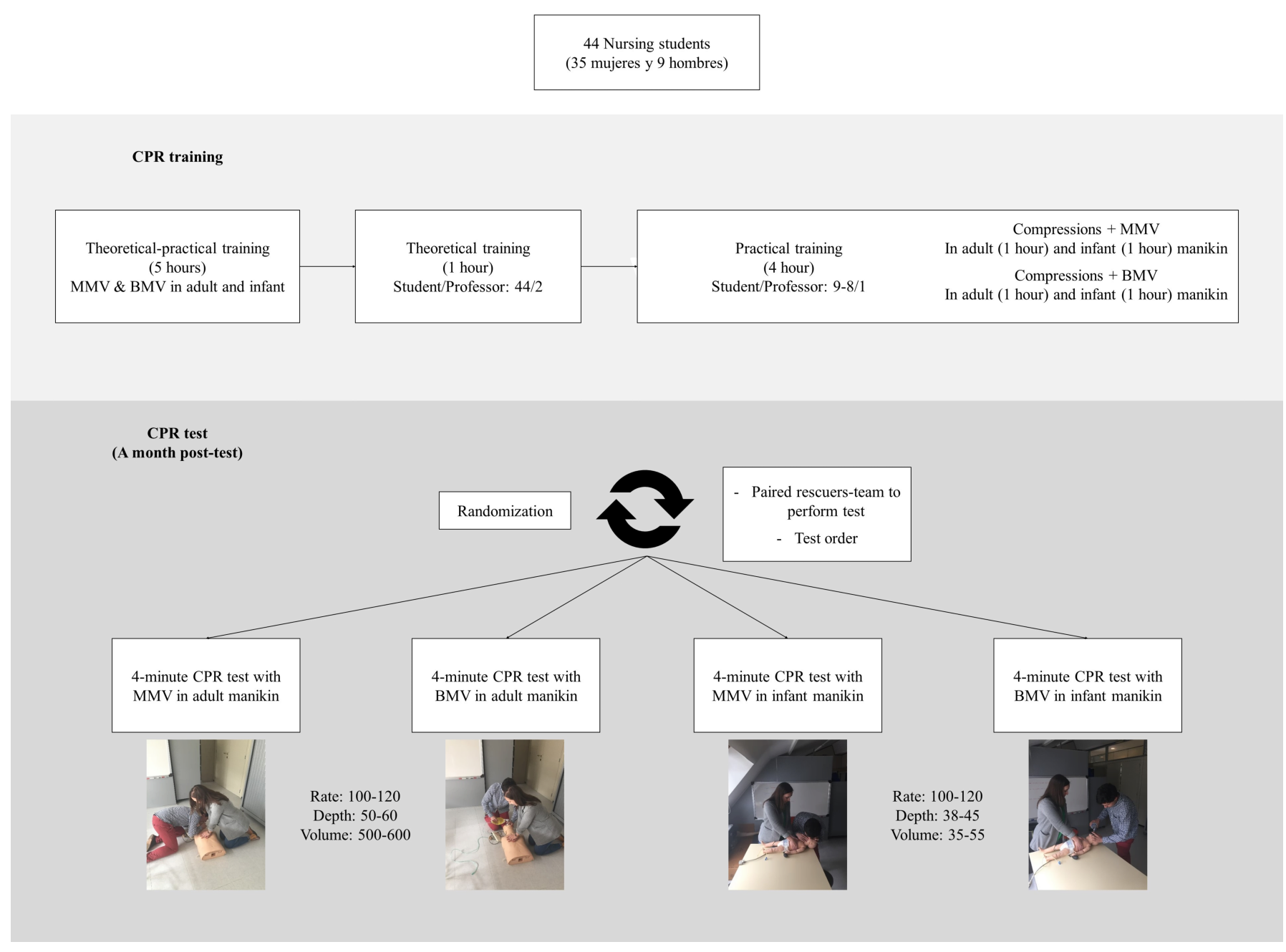

F I G U R E 1. Flow chart. Study design.

MMV: Mouth-to-Mouth Ventilation. BMV: Bag-valve-Mask Ventilation. Rate: in compressions per minute; Depth: in mm; Volume: in $\mathrm{ml}$.

including all students in the second year of their degree course who voluntarily agreed to take part in the study. The exclusion criteria consisted of having some kind of physical limitation that impeded CPR delivery or not having carried out any one of the evaluation tests. No participant was excluded. The data was anonymised. This research was approved by the Ethics Committee of Pontevedra University School of Nursing and complied with the Helsinki Declaration's ethical principles. $80 \%$ of the students were female $(\mathrm{N}=35)$ and $20 \%$ were male $(\mathrm{N}=9)$. The age of the overall sample was $25 \pm 6$ years of age; weight was $67 \pm 14 \mathrm{~kg}$ and height was $166 \pm 10 \mathrm{~cm}$.

\subsection{Design}

A quasi-experimental random cross-over design study was carried out (Fig. 1). Research Randomizer (www.randomizer. org) computer software program was used to form the pairs that would carry out the test jointly and to assign the order in which the four tests would be performed.

\subsection{CPR training}

All of the participants took part in a 5-hour practical and theoretical CPR training session using MMV and BMV with both adult and infant victims. The theoretical training was provided by two university teachers in the form of a 60 minute a presentation-based lecture. The practical training comprised a 60-minute CPR training session using MMV on adult victims, followed by a 60 -minute CPR session using MMV on infant victims. This was followed by a 60 -minute CPR training session using BMV on adult victims and a further 60-minute session using BMV on infant victims. The student/teacher proportion in the theoretical session was 44/2, while the proportion in the practical sessions was 8-9/1.

The practical training was carried out on a Laerdal ResusciAnne QCPR ${ }^{\circledR}$ (Stavanger, Norway) adult manikin and a Laerdal Resusci Baby QCPR $®$ infant manikin, using Laerdal Simpad ${ }^{\circledR}$ software version 1.6 for visual feedback (Fig. 2). The software was configured in accordance with the recommendations of the European Resuscitation Council (ERC) [1, 22]. Regarding ventilation volumes in infant victims, a delivery of between 35 and $55 \mathrm{ml}$ of air per breath was chosen as being correct, as this is a value which is suggested by 


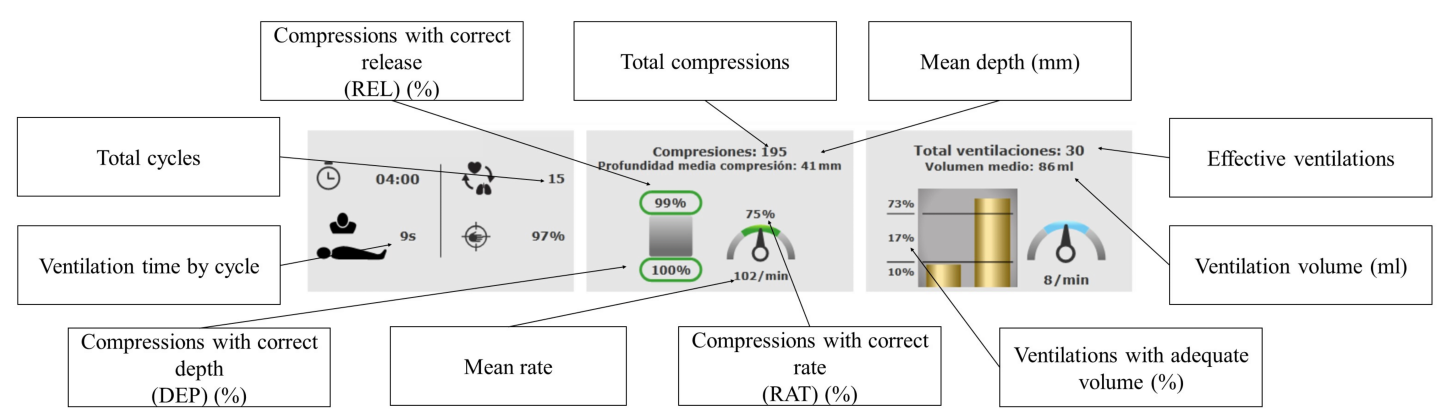

Compression quality (\%): (REL + DEP + RAT) / 3

Effective ventilations (\%): Total ventilations captured by software x $100 /$ Ventilations attempted captured by the researcher

Ratio of ventilation to time: Ventilations by cycle / Ventilation time by cycle

CPR quality (\%): (Compression quality + Ventilations with adequate volume) / 2

F I G U R E 2. Description of the study variables by Laerdal Session Viewer Software.

Study variables. Calculation formulas of some variables. mm: millimetres; ml: millilitres.

Rodríguez-Núñez for mechanical ventilation in 3-month-old pediatric victims weighing approximately $5.5 \mathrm{~kg}$ [23]. For the BMV technique, Laerdal's self-inflating Bag II adult w/mask no. 5, with a capacity of $1600 \mathrm{ml}$, and Laerdal's self-inflating Bag II infant w/mask no. 2, with a capacity of $500 \mathrm{ml}$, were used.

\subsection{CPR tests}

The CPR evaluation tests took place a month after training had finished. The participants were randomly paired to carry out four CPR tests. Adult manikins were used in two of these tests adult manikins were used, with two different ventilation techniques (MMV and BMV). The two remaining tests were carried out on infant manikins, using the same ventilation techniques as on an adult. The order of the tests performed by each pair was randomly assigned. Each test lasted 4 minutes in in all, during which time one of the participants began delivering ventilations and the other compressions, switching tasks half-way through the test. The two tests with the adult manikin were performed with the ERC-recommended compression to ventilation ratio for adult victims (30/2) [1] The two tests with the infant manikin were carried out with the ERCrecommended compression to ventilation ratio for paediatric victims (15/2), preceded by 5 initial insufflations [22] The instruments used for CPR evaluation were the same as for the practical training, and the same configurations were applied.

\subsection{Variables}

All the variables were provided by the above devices. Despite different protocols in adult and pediatric victims, all variables were compared. In all cases (adult MMV; adult BMV; pediatric MMV; pediatric BMV) the following variables were recorded and compared according to the type test.

\subsubsection{Compression variables}

The following compression variables were recorded for the study: mean rate in compressions per minute, mean depth in $\mathrm{mm}$, compressions performed with correct release (REL), in percentage terms, compressions performed with correct depth (DEP), in percentage terms, compressions with correct rate (RAT), in percentage terms, and total number of compressions. These variables were provided by Laerdal's Session Viewer ${ }^{\circledR}$ software (Fig. 2). The compression quality variable was calculated, in percentage terms, by using the formula [(REL + DEP + RAT)/3]. 


\subsubsection{Ventilation variables}

The following ventilation variables were also recorded: ventilation time per cycle in seconds, effective ventilations, ventilation volume in $\mathrm{ml}$, ventilations with adequate volume, in percentage terms. These variables were provided by Laerdal's Session Viewer ${ }^{\circledR}$ software (Fig. 2). The ventilations attempted by the participants were recorded by one of the researchers in real time. Effective ventilations in percentage terms were calculated via the following formula [effective ventilations captured by software $\mathrm{x} 100$ / attempted ventilations recorded by the researcher]. The ratio of ventilation to time was measured in ventilations per second and calculated via the following formula [Ventilations per cycle / Ventilation time per cycle]. Ventilations per cycle were calculated previously by relating the number of ventilations to the number of cycles.

\subsubsection{CPR quality variables}

CPR quality in percentage terms was calculated via the following formula [(compression quality + correct volumes of ventilations)/2].

The formulae applied to calculate the variables are based on studies carried out previously with simulators of similar characteristics [24].

\subsection{Statistical analysis}

The statistical analysis was performed with IBM SPSS Statistics 20 software for Windows (SPSS, Inc, Armonk, NY, USA). The variables were described by measures of central tendency (mean), measures of dispersion (standard deviation) and confidence estimates (confidence intervals).

In the comparisons between the four tests, firstly we used the Shapiro Wilk test to verify that the variables were normally distributed. For the variables that met the normality criteria, we used a repeated measures ANOVA test with a Bonferroniadjusted $p$ value of 0.05 . For the variables that did not meet the normality criteria, we used a Kruskal-Wallis test for related samples. In these cases, the Bonferroni correction was applied in the pairwise comparisons using the Wilcoxon signed rank test with an adjusted $p$ value between the number of comparisons carried out [0.05/6], giving rise to a $p$ value $=0.008$. For the comparisons that showed significant differences, we calculated the effect size. In the case of the variables that met the normality criterion, this was calculated using Cohen's test, while Rosenthal's test was used for the variables that did not meet said criterion.

\section{Results}

The results of the CPR variables derived from the four tests carried out in pairs are shown in Table 1. Both the mean rate and the mean depth of compressions complied with the ERC's 2015 guidelines recommendations. No significant differences were observed in relation with compression quality, with average values of $78 \%$ (MMV infant); $81 \%$ (BMV infant); $84 \%$ (MMV adult) and $86 \%$ (BMV adult) ( $p>0.008$ ). With reference to ventilations, significantly higher values were observed in the MMV tests as opposed to the BMV tests: Adult MMV (98 $\pm 7 \%)$; Adult BMV $(84 \pm 17 \%) ;(p=0.003$;
$\mathrm{TE}=0.44) /$ Infant MMV $(97 \pm 11 \%)$; Infant BMV $(76 \pm$ $26 \%) ;(\mathrm{p}=0.001 ; \mathrm{TE}=0.59)$. A trend towards higher than recommended volumes were observed when MMV was used in the adult MMV $(737 \pm 1052 \mathrm{ml})$, where they were significantly higher than those observed when BMV was used (440 \pm 149 $\mathrm{ml})(\mathrm{p}=0.008 ; \mathrm{TE}=0.40)$. With regard to the infant, higher than recommended volumes were observed when BMV was used $(61 \pm 26 \mathrm{ml})$, where they were significantly higher than those observed when MMV was used $(42 \pm 9 \mathrm{ml})(\mathrm{p}=0.001$; $\mathrm{TE}=0.51)$. No significant differences were observed in the ratio of ventilation to time in the infant test: MMV $(0.45 \pm$ 0.08 ventilations per second); $\mathrm{BMV}(0.49 \pm 0.12$ ventilations per second) $(\mathrm{p}=0.01)$. However, what was observed were significant differences between the adult tests: MMV $(0.32 \pm$ 0.06 ventilations per second); BMV $(0.40 \pm 0.08$ ventilations per second) $(\mathrm{p}<0.001 ; \mathrm{TE}=0.59)$. The highest overall $\mathrm{CPR}$ quality was achieved when MMV was used on the infant victim $(68 \pm 16 \%)$, revealing significantly higher values than the other tests: MMV adult $(52 \pm 10 \%)(\mathrm{p}=0.001 ; \mathrm{TE}=1.23)$; BMV adult $(48 \pm 10 \%)(\mathrm{p}<0.001 ; \mathrm{TE}=1.53)$; BMV infant $(55 \pm 12 \%)(\mathrm{p}<0.001 ; \mathrm{TE}=0.94)$.

\section{Discussion}

In this study, a five-hour practical and theoretical training session involving nursing students was held, after which the participants had acquired skills enabling them to perform two basic ventilation techniques (MMV and BMV) on simulation manikins. The aim of this study was to evaluate said skills with adult and infant manikins.

With regard to the compression variables, no differences that might have influenced the CPR quality were observed. Nor did any other studies reveal any differences in the compression variables when evaluating different ventilation techniques performed on a manikin $[20,25]$. The compression values were high quality (higher than 70\%) and are in line with the values recommended under current guidelines [1, 22, 26]. Other studies with samples from nursing or nursing students revealed lower compression quality results than those observed by us $[17,20]$. The compression quality results in this study are higher than the ventilation values, which has already been described in other training programmes [27]. This could be due to the fact that performing quality chest compressions entails less training time than ventilations, which entail greater difficulty $[1,12]$.

Ventilation effectiveness is hugely important for a cardiac arrest victim's chances of survival [28]. In a cardiac arrest, oxygen reserves are maintained sufficiently high during the initial minutes, and therefore compression-only CPR could be a suitable strategy [8]. However, in cases of paediatric cardiac arrest, when a long time has passed or if the cause is respiratory, ventilations play a vital role in the victim's prognosis $[6,7,9,10]$. This is why ventilation effectiveness is a highly valuable quality criterion, as low results would indicate an interruption in compressions which has been of no benefit to the victim [28]. The participants in this study have demonstrated greater effectiveness using the MMV technique as opposed to BMV, both in adults and infants. Evidence indicating greater effectiveness using the MMV technique exists 
TA B L E 1. Four CPR test variables performed.

$\mathrm{N}=22$ nursing student by pairs Mouth-to-mouth ventilation (MMV) Bag-valve-mask ventilation (BMV) MMV vs BMV

\begin{tabular}{|c|c|c|c|c|c|c|}
\hline & & Mean (SD) & CI & Mean (SD) & $\mathrm{CI}$ & \multirow{3}{*}{$\begin{array}{c}\mathrm{p}=0.004 \dagger \\
(0.56)\end{array}$} \\
\hline \multirow{5}{*}{ Mean rate } & \multirow{2}{*}{ Adult A } & 115 & 111 & 111 & 108 & \\
\hline & & $(8)$ & 119 & (6) & 114 & \\
\hline & \multirow{2}{*}{ Infant I } & 112 & 107 & 112 & 107 & \multirow{2}{*}{$\mathrm{p}=0.80 \dagger$} \\
\hline & & $(10)$ & 116 & $(11)$ & 117 & \\
\hline & A vs I & \multicolumn{2}{|c|}{$\mathrm{p}=0.33 \dagger$} & \multicolumn{2}{|c|}{$\mathrm{p}=0.66 \dagger$} & \\
\hline \multirow{5}{*}{ Mean depth (mm) } & \multirow{2}{*}{ Adult A } & 53 & 52 & 53 & 51 & \multirow{2}{*}{$\mathrm{p}=0.50^{*}$} \\
\hline & & (2) & 54 & (3) & 55 & \\
\hline & \multirow{2}{*}{ Infant I } & 41 & 40 & 41 & 41 & \multirow{2}{*}{$\mathrm{p}=0.61^{*}$} \\
\hline & & (2) & 42 & (2) & 42 & \\
\hline & A vs I & \multicolumn{2}{|c|}{$\mathrm{p}<0.001 *(0.62)$} & \multicolumn{2}{|c|}{$\mathrm{p}<0.001 *(0.62)$} & \multirow{3}{*}{$\mathrm{p}=0.39^{*}$} \\
\hline \multirow{5}{*}{ Compression quality (\%) } & \multirow{2}{*}{ Adult A } & 84 & 79 & 86 & 80 & \\
\hline & & (12) & 89 & (12) & 91 & \\
\hline & \multirow{2}{*}{ Infant I } & 78 & 72 & 81 & 74 & \multirow{2}{*}{$\mathrm{p}=0.41^{*}$} \\
\hline & & (14) & 85 & $(15)$ & 87 & \\
\hline & A vs I & $\mathrm{p}=$ & & & & \multirow{3}{*}{$\begin{array}{c}\mathrm{p}=0.003 * \\
(0.44)\end{array}$} \\
\hline \multirow{5}{*}{ Effective ventilation (\%) } & \multirow{2}{*}{ Adult A } & 98 & 95 & 84 & 76 & \\
\hline & & (7) & 101 & (17) & 91 & \\
\hline & \multirow{2}{*}{ Infant I } & 97 & 92 & 76 & 65 & \multirow{2}{*}{$\begin{array}{c}\mathrm{p}<0.001 * \\
\quad(0.59)\end{array}$} \\
\hline & & (11) & 101 & (26) & 88 & \\
\hline & A vs I & $\mathrm{p}=$ & & & & \multirow{3}{*}{$\begin{array}{c}\mathrm{p}=0.008^{*} \\
(0.40)\end{array}$} \\
\hline \multirow{5}{*}{ Ventilation volume (ml) } & \multirow{2}{*}{ Adult A } & 737 & 271 & 440 & 374 & \\
\hline & & (1052) & 1204 & (149) & 506 & \\
\hline & \multirow{2}{*}{ Infant I } & 42 & 38 & 61 & 49 & $\mathrm{p}=0.001^{*}$ \\
\hline & & (9) & 46 & $(26)$ & 73 & $(0.51)$ \\
\hline & A vs I & $\mathrm{p}<0.0$ & & $\mathrm{p}<0$ & & \\
\hline & Adult A & 0.32 & 0.29 & 0.40 & 0.37 & $\mathrm{p}<0.001^{*}$ \\
\hline time (ventilations/sec) & Hum & $(0.06)$ & 0.35 & $(0.08)$ & 0.44 & $(0.59)$ \\
\hline & & 0.45 & 0.41 & 0.49 & 0.44 & \\
\hline & Intant 1 & $(0.08)$ & 0.48 & $(0.12)$ & 0.55 & $\mathrm{p}=0.01^{*}$ \\
\hline & A vs I & $\mathrm{p}<0.0$ & & $\mathrm{p}=0$ & & \\
\hline CPR auality (\%) & Adult A & 52 & 47 & 48 & 43 & $\mathrm{n}=0.19 \div$ \\
\hline CPK quality (\%) & Adult A & $(10)$ & 56 & $(10)$ & 53 & $\mathrm{p}=0.19 \uparrow$ \\
\hline & Infant I & 68 & 61 & 55 & 49 & $\mathrm{p}<0.001 \dagger$ \\
\hline & InIant 1 & $(16)$ & 74 & (12) & 60 & $(0.94)$ \\
\hline & A vs I & $\mathrm{p}=0.0$ & & $\mathrm{p}$ & & \\
\hline
\end{tabular}

* Friedman test for related samples with Bonferroni correction aplied with Wilcoxon signed ranked test $(p=0.008)$.

ANOVA test for repeated measures with Bonferroni correction $(p=0.05)$.

In brackets, the effect size calculation with Rosenthal or Cohen test.

$[20,25]$. BMV is a technique that involves greater difficulty than MMV and it is therefore less simple to carry out adequate insufflations with said technique [21, 29]. Its effectiveness depends to a large extent on the rescuer's skills [23]. The results described would suggest that the training received by nursing students was not sufficient to adequately master the BMV technique.

When BMV was used, the results show significantly lower volumes in the adult and significantly higher ones in the infant. The MMV volume in the adult is highly variable, with a trend towards excessive volumes, in keeping with previous studies [25, 27]. With BMV, the values show less variability, with a trend towards insufficient volumes, also in keeping with previous studies $[17,25]$.In the infant, a trend towards adequate volumes with MMV and excessive volumes with BMV are observed, which is also in line with previous studies [20]. Ventilations with excessive volume cause an increase in intrathoracic pressure which affects cardiac output during the compression phase, rendering them less effective [16, 29, 30]. In turn, the ventilations also affect airway pressure, which increases gastric inflation and the possible risk of bronchoaspiration [29]. Nursing students require a higher level of training in order to optimise ventilation volumes and avoid, insofar as possible, the delivery of excessive volumes.

Normally, healthcare workers tend to ventilate using highfrequency ventilation (HFV) during CPR, both in adult and 
paediatric victims [29, 31]. HFV increases intrathoracic pressure in the same way as delivering excessive volumes does [16]. CA victims who receive ventilations in more than half of the pauses taken during compressions show greater survival rates [28]. The ERC defends the importance of reducing ventilation times, recommending one-second-long insufflations, without allowing them to be too sharp or forced [1]. Jo et al suggest placing greater emphasis on ventilation metrics, pointing out that they could be included as a component with which to evaluate CPR quality. Following recommendations, they propose a delivery rate of 0.5 ventilations per second during interruptions in chest compressions [32]. In this study, both techniques have been shown to be far from said value of 0.5 in adult simulations. In the infant simulations, values closer to 0.5 were observed.

CPR quality is not always optimal, even when performed by doctors and nurses with prior training [14-16]. In this study, the nursing students achieved acceptable results insofar as quality is concerned, especially when using MMV on an infant. Other studies have also observed acceptable quality results for CPR with ventilation [20, 27]. Different studies have evaluated the difficulty of performing CPR with BMV $[17,18]$. Mastering the BMV technique requires more training time than the MMV technique [21]. A lack of experience or training leads to human error when delivering ventilations via BMV, which can be rectified by increasing training [23]. Despite the fact that the quality results obtained by the nursing students were not low, it is necessary to find a training method that allows ventilation delivery to be improved, especially when using BMV.

The nursing student sample received a 5-hour practical and theoretical training session. However, in spite of all these measures, high quality results were not obtained. The values obtained when carrying out compressions did exceed what was considered the minimum quality level [26]. but ventilation skills required more time spent on training, especially with the BMV technique [17, 18, 25]. One option for improving these quality results could be to carry out self-guided re-training sessions using visual feedback in real time after an initial training session like the one in this design.

Given that a certain risk of transmitting disease exists during mouth-to-mouth contact [33], up to $40 \%$ of rescuers who perform CPR do not use MMV [9]. As for BMV, it is a widely used technique, perhaps the one used most in emergency and out-of-hospital situations [29]. This enables rescuers to deliver ventilations without direct contact with the victim's mouth and providing high concentrations of oxygen. After considering COVID-19 as a pandemic disease, the chances of MMV may be further reduced. The risks of transmission associated with the resuscitation components are not clear, but the ERC guidelines do not advise MMV so as to safeguard the safety of the rescuer. However, regarding pediatric recommendations, there is more discussion around the topic. Although the importance of preventing transmission is continually pointed out, ventilations are more recommended than in adults [34, 35]. The new recommendations from the COVID-19 era advise against teaching MMV and warn about the risk of aerosol generation with BMV in less-skilled or uncomfortable teams. BMV is the recommended ventilation technique for professionals with adequate skills in its use during the COVID-19 era [34]. The results obtained in the study would suggest that new methods to extend a program of similar characteristics ought to be trialed. If students are to master its use, then University teachers are faced with the challenge of promoting training using the BMV technique.

\section{Practical applications}

This study provides evidence relating to nursing students' ventilation skills using different techniques after receiving the same amount of training time for both of these techniques. Mouth-to-mouth ventilation obtained good effectiveness values, but bag-valve-mask ventilation resulted in fewer insufflations reaching the lungs. This would indicate that insofar as MMV is concerned, the training received was sufficient for students to master the technique in both adults and infants. However, the results obtained in the study suggest that new methods to extend a training programme of similar characteristics ought to be trialled. Currently, University teachers are faced with the challenge of promoting training with the BMV technique if students are to fully master its use.

Training of the type carried out in this study might be useful as a first step, but would need to be reinforced over time through ongoing training with short, practical sessions in order to promote improved learning [36-38]. Priority should be given to improving nursing students' training [39]. a good option being to use different times during their university degree to carry out training sessions, with the learning objectives becoming progressively more complex. With regard to healthcare workers, it would be useful to hold monthly training sessions using manikins with visual feedback. The evidence clearly shows that the success of ventilation with the BMV technique depends on the rescuer's skill, experience and training $[12,17,18,29]$. Acquiring the skills necessary to master the technique through training is a priority objective and a responsibility for both university teachers and healthcare professionals alike.

With respect to the COVID-19 era, training with the BMV should be prioritized so that future professionals can master the technique. Training using a high-efficiency particulate air (HEPA) filter or a heat and moisture exchanger (HME) filter between the self-inflating bag and the mask would be interesting and highly recommendable. Similarly, performing CPR training using personal protective equipment (PPE) could also improve technique efficiency during the pandemic.

\section{Limitations}

The use of manikins is widespread in scientific literature, thus providing valuable information on controlled situations and making it possible to carry out random studies that would be unlikely in any other way. However, a simulated environment is limited in comparison with a real-life situation, which should always be borne in mind. Participants in a simulated environment never experience the same stress levels as they would in a real-life situation, and therefore should not be extrapolated to real-life situations without this aspect being taken into account. Furthermore, the sample size used 
in this study, which employed non-probability convenience sampling, was limited. In this case, the size was adapted to the number of students in an academic year, and it would be interesting to carry out similar designs with a higher sampling size.

\section{Conclusion}

A 5-hour practical and theoretical training programme with visual feedback is sufficient for nursing students to be able to perform high quality chest compressions on adult and infant manikins. Mouth-to-mouth ventilation skills present acceptable results in both age groups (especially in infants). The results with the bag-valve-mask technique indicate that the students had not yet managed to master the technique in either victim. Trainings sessions with longer practice times are likely to be required for the bag-valve-mask ventilation. Nursing students require new innovative strategies that complement similar training in order to master the bag-valve-mask ventilation technique. New studies should be aimed at achieving a strategy that enables these skills to be assimilated correctly.

\section{ACKNOWLEDGMENTS}

The authors acknowledge to the volunteers participated in the study.

\section{CONFLICT OF INTEREST}

The authors declare no competing interests.

\section{FUNDING INTEREST}

This research did not receive any specific grant from funding agencies in the public, commercial, or not-for-profit sectors.

\section{AUTHORS CONTRIBUTIONS}

M O-A, MT H-G and R B-F designed the research study. M O-A, MT H-G and M S-F performed the research. F F-M provided help and advice with the CPR test and with feedback software. M O-A analyzed the data. M O-A, R B-F and MT $\mathrm{H}-\mathrm{G}$ wrote the manuscript. All authors contributed to editorial changes in the manuscript. All authors read and approved the final manuscript.

\section{ETHICS APPROVAL AND CONSENT TO PARTICIPATE}

This research was approved by Pontevedra University School of Nursing Ethics Committee and complied with the Helsinki Declaration's ethical principles.

\section{REFERENCES}

[1] Perkins GD, Handley AJ, Koster RW, et al. European Resuscitation Council Guidelines for Resuscitation 2015 Section 2. Adult basic life support and automated external defibrillation. Resuscitation. 2015;95:8199.
[2] Engdahl J, Bång A, Karlson BW, et al. Characteristics and outcome among patients suffering form out of hospital cardiac arrest of non-cardiac aetiology. Resuscitation. 2003;57:33-41.

[3] Hess EP, Campbell RL, White RD. Epidemiology, trends, and outcome of out-of-hospital cardiac arrest of non-cardiac origin. Resuscitation. 2007;72:206-207.

[4] Donoghue AJ, Nadkarni V, Berg RA, et al. Out-of-hospital pediatric cardiac arrest: An epidemiologic review and assessment of current knowledge. Ann Emerg Med. 2005;46:512-522.

[5] Atkins DL, Everson-Stewart S, Sears GK, et al. Epidemiology and outcomes from out-of-hospital cardiac arrest in children: the resuscitation outcome consortium epistry-cardiac arrest. Circulation. 2009;119:14841491.

[6] Meaney PA, Nadkarni VM, Cook EF, et al. Higher survival rates among younger patients after paediatric intensive care unit cardiac arrests. Pediatrics. 2006;118:2424-2433.

[7] Kitamura T, Iwami T, Kawamura T, et al. Bystander-initiated rescue breathing for out-of-hospital cardiac arrests of noncardiac origin. Circulation. 2010;122:293-299.

[8] Iwami T, Kawamura T, Hiraide A, et al. Effectiveness of bystanderinitiated cardiac-only resuscitation for patients with out-of-hospital cardiac arrest. Circulation. 2007;116:2900-2907.

[9] Berg RA, Hilwig RW, Kern KB, et al. Simulated mouth-to-mouth ventilation and chest compressions (bystander cardiopulmonary resuscitation) improves outcome in a swine model of prehospital pediatric asphyxia cardiac arrest. Crit Care Med. 1999;27:1893-1899.

[10] Berg RA, Hilwig RW, Kern KB, et al. "Bystander" chest compressions and assisted ventilation independently improve outcome from piglet asphyxia pulseless "cardiac arrest." Circulation .2000;101:1743-1748.

[11] Newell C, Grier S, Soar J. Airway and ventilation management during cardiopulmonary resuscitation and after successful resuscitation. Crit Care. 2018;22:190.

[12] Perkins GD, Olasveengen TM, Maconochie I, et al. European Resuscitation Council Guidelines for resuscitation: 2017 update. Resuscitation. 2017;123:43-50.

[13] Nyman J, Sihvonen M. Cardiopulmonary resuscitation skills in nurses and nursing students. Resuscitation. 2000;47:179-184.

[14] Abella BS, Alvarado JP, Myklebust H, et al. Quality of cardiopulmonary resuscitation during in-hospital cardiac arrest. JAMA. 2005;293:305-310.

[15] Smith KK, Gilcreast D, Pierce K. Evaluation of staff's retention of ACLS and BLS skills. Resuscitation. 2008;78:59-65.

[16] Dine CJ, Gersh RE, Leary $\mathrm{M}$, et al. Improving cardiopulmonary resuscitation quality and resuscitation training by combining audiovisual feedback and debriefing. Crit Care Med. 2008;36:2817-2822.

[17] Kardong-Edgren SE, Oermann MH, Odom-Maryon T, et al. Comparison of two instructional modalities for nursing student CPR skill acquisition. Resuscitation. 2010;81:1019-1024.

[18] Isbye DL, Høiby P, Rasmussen MB, et al. Voice advisory manikin versus instructor facilitated training in cardiopulmonary resuscitation. Resuscitation. 2008;79:73-81.

[19] Pan J, Zhu JY, Kee HS, et al. A review of compression, ventilation, defibrillation, drug treatment, and targeted temperature management in cardiopulmonary resuscitation. Chinese Medical Journal. 2015;128:550554.

[20] Soar J, Nolan JP. Airway management in cardiopulmonary resuscitation. Curr Opin Crit Care. 2013;19:181-187.

[21] Maconochie IK, Bingham R, Eich C, et al. European Resuscitation Council Guidelines for Resuscitation 2015 Section 6. Paediatric life support. Resuscitation. 2015;95:223-248.

[22] Rodríguez-Núñez A. Ventilation during pediatric CPR. Current Pediatric Reviews. 2013;9:109-114.

[23] Barcala-Furelos R, Abelairas-Gómez C, Aranda-García S, et al. Is it feasible "scoop and run while playing" resuscitation on a Rescue Water Craft? A randomized simulation study with lifeguards. Am J Emerg Med. 2020;38:618-623.

[24] Adelborg K, Dalgas C, Lerkevang Grove E, et al. Mouth-to-mouth ventilation is superior to mouth-to-pocket mask and bag-valve-mask ventilation during lifeguard CPR: A randomized study. Resuscitation 2011;82:618-622. 
[25] Santos-Folgar M, Otero-Agra M, Fernández-Méndez F, et al. Ventilation during cardiopulmonary resuscitation in the infant. Mouth to mouth and nose, or bag-valve-mask? A quasi-experimental study. An Pediatr (Barc). 2018;89:272-278.

[26] Perkins GD, Colquhoun M, Simons R. Training manikins. ABC of resuscitation. 2004:97-101.

[27] Aranda-García S. Herrera-Pedroviejo E, Abelairas-Gómez C. Basic LifeSupport learning in undergraduate students of Sports Sciences: Efficacy of 150 minutes of training and retention after eight months. Int J Environ Res Public Heath. 2019;16:4771.

[28] Chang MP, Lu Y, Leroux B, et al. Association of ventilation with outcomes from out-of-hospital cardiac arrest. Resuscitation 2019;141:174181.

[29] Khoury A, Hugonnot S, Cossus J, et al. From Mouth-to-Mouth to BagValve-Mask Ventilation: Evolution and characteristics of actual devices - A review of the literature. Biomed Res Int. 2014;2014:762053.

[30] Aufderheide TP, Sigurdsson G, Pirrallo RG, et al. Hyperventilationinduced hypotension during Cardiopulmonary Resuscitation. Circulation. 2004;109:1960-1965.

[31] Niebauer JM, White ML, Zinkan JL, et al. Hyperventilation in pediatric resuscitation: performance in simulated pediatric medical emergencies. Pediatrics. 2011;128:e1195-200.

[32] Jo S, Lee JB. Ventilation during out-of-hospital cardiac arrest. Resuscitation. 20201;146:268.

[33] Christian MD, Loutfy M, McDonald LC, et al. Possible SARS coronavirus transmission during cardiopulmonary resuscitation. Emerg Infect Dis. 2004;10:287-293.
[34] Nolan JP. European Resuscitation Council COVID-19 Guidelines [Internet]. 2020; Available in: https : //www .erc.edu/covid.

[35] Perkins GD, Morley PT, Nolan JP, et al. International Liaison Committee on Resuscitation: COVID-19 Consensus on Science, Treatment Recommendations and Task Force Insights. Resuscitation. 2020;151:145-147.

[36] Oermann MH, Kardong-Edgren SE, Odom-Maryon T. Effects of monthly practice on nursing students' CPR psychomotor skill performance. Resuscitation. 2011;82:447-453.

[37] Johnson M, Peat A, Boyd L, et al. The impact of quantitative feedback on the performance of chest compression by basic life support trained clinical staff. Nurse Education Today. 2016;45:163-166.

[38] Toubasi S, Alosta MR, Darawad MW, et al. Impact of simulation training on Jordanian nurses' performance of basic life support skills: A pilot study. Nurse Education Today. 2015;35:999-1003.

[39] Madden C. Undergraduate nursing students' acquisition and retention of CPR knowledge and skills. Nurse Education Today. 2006;26:218-227.

How to cite this article: Martín Otero-Agra, María Teresa Hermo-Gonzalo, Myriam Santos-Folgar, Felipe Fernández-Méndez, Roberto Barcala-Furelos. Assessing Ventilation Skills by Nursing Students in Paediatric and Adult Basic Life Support: A Crossover Randomized Simulation Study Using Bag-Valve-Mask (BMV) Vs Mouth-to-Mouth Ventilation (MMV). Signa Vitae. 2020;16(2):44-51. doi:10.22514/sv.2020.16.0072. 